\title{
Cryopreservation of rabbit corneas: assessment by microscopy and transplantation
}

\author{
L P FONG, C J HUNT, M J TAYLOR, AND D E PEGG
}

\begin{abstract}
From the MRC Medical Cryobiology Group, University Department of Surgery, Douglas House, Trumpington Road, Cambridge CB2 $2 A H$.
\end{abstract}

SUMmARY Rabbit corneas were frozen and thawed by three methods and compared by full thickness transplantation as well as specular microscopy, histology, and transmission electron microscopy. Two of the methods used a recently described technique, in which the excised cornea was immersed in a potassium-rich buffered solution containing the cryoprotectant dimethyl sulphoxide $\left(\mathrm{Me}_{2} \mathrm{SO}, 2 \mathrm{~mol} / \mathrm{l}\right)$. This solution was designed to restrict the loss of intracellular potassium and to prevent cell swelling at low temperatures. In one group the corneas were frozen and thawed surrounded by $5 \mathrm{ml}$ of medium, while in the second group corneas were drained of excess fluid and frozen in air. The third group consisted of corneas cryopreserved by Capella and colleagues' method. All the cryopreserved corneas were damaged, but those that had been frozen in air after exposure to the new medium showed better structure and function than corneas frozen by either of the other two techniques.

It has been reported that corneas cryopreserved by the methods of Mueller' and Capella et al. ${ }^{2}$ are as effective in clinical transplantation as fresh nonfrozen material. ${ }^{34}$ Nevertheless, neither method of corneal storage has gained general acceptance. Capella et al. ${ }^{2}$ reported a high proportion of surviving endothelial cells when assessment was made by histochemical methods, and Van Horn et al. confirmed this finding using transmission and scanning electron microscopy. ${ }^{56}$ However, the reliability of histochemical assays as predictors of viability may be questioned, ' and more recent studies employing both electron and specular microscopy have shown grossly disorganised endothelium without barrier function. ${ }^{84}$

Mueller used a conventional balanced salt solution as a vehicle for the introduction and removal of the cryoprotectant dimethyl sulphoxide $\left(\mathrm{Me}_{2} \mathrm{SO}\right)$, but Capella and colleagues employed a solution containing only sucrose and albumin in addition to $\mathrm{Me}_{2} \mathrm{SO}$. Corneas exposed to this medium have been shown to be severely dehydrated and to have lost significant amounts of sodium and potassium. " Disturbances of the ion and water content of tissues during preservation have been widely investigated. In one such study it was found that increasing the concentration of potassium and substituting a high molecular Correspondence to Dr D E Pegg. weight zwitterionic buffer for some of the chloride resulted in improved cryopreservation of smooth muscle tissue. ${ }^{11}{ }^{12} \mathrm{~A}$ similar solution has been proposed for cryopreservation of the cornea. ${ }^{1314}$ It contains the buffer $\mathrm{N}$-tris (hydroxymethyl)-methyl-2aminoethane sulphonic acid (TES) and is designated CPTES using two modes of storage. In the first, corneas were frozen, stored and thawed while surintroduction and removal of 1 and 2 molar $\mathrm{Me}_{2} \mathrm{SO}$ in this solution at $0^{\circ} \mathrm{C}$.

In this paper we describe the cryopreservation of rabbit corneas after incubation in 2 molar $\mathrm{Me}_{2} \mathrm{SO}$ in CPTES using two modes of storage. In the first, corneas were frozen, stored and thawed while surrounded by $5 \mathrm{ml}$ of the $2 \mathrm{M} . \mathrm{Me}_{2} \mathrm{SO}-\mathrm{CPTES}$ medium; in the second method, following the work of Mueller ${ }^{1}$ and Taylor et al. ${ }^{8}$ corneas that had been permeated by the cryoprotectant were then drained and frozen surrounded by air. For comparison, a third group of rabbit corneas was cryopreserved by the technique of Capella et al. ${ }^{2}$ Survival was assessed by light microscopy and transmission electron microscopy of corneas immediately after thawing and removal of the cryoprotectant, and by transplantation of full thickness corneal grafts. The grafts were evaluated by slit-lamp examination and in-vivo specular microscopy. After one week they were removed, corneal 
thickness was measured on the in-vitro specular microscope, and histological examination was carried out.

\section{Materials and methods}

\section{PREPARATION OF CORNEAS}

Corneas were obtained from New Zealand White rabbits $(2-2.5 \mathrm{~kg})$ that had been killed with pentobarbitone. The excised corneas were prepared by the method of Dikstein and Maurice's and were mounted on plastic support rings to prevent wrinkling and distortion. Control corneas were prepared by the same method but were placed in glutathione bicarbonate Ringer's solution, ${ }^{8}$ gassed with $95 \%$ oxygen, $5 \%$ carbon dioxide $(\mathrm{pH} 7.4)$ at $0^{\circ} \mathrm{C}$, and transplanted without delay.

\section{CRYOPRESERVATION PROCEDURE}

CPTES method. Corneas were immersed endothelial side uppermost in $5 \mathrm{ml}$ of 2 molar $\mathrm{Me}_{2} \mathrm{SO}$ in CPTES solution at $0^{\circ} \mathrm{C}$ for 20 minutes; $25 \mathrm{ml}$ polypropylene vials with screw caps were used for this purpose. CPTES contained (mmol/l) $\mathrm{Na}^{+}(31), \mathrm{K}^{+}(100), \mathrm{Mg}^{++}$ $(0.78), \mathrm{Cl}^{-}(30), \mathrm{HCO}_{3}^{-}(30), \mathrm{H}_{2} \mathrm{PO}_{4}^{-}(1), \mathrm{SO}_{4}{ }^{--}$ $(0.78)$, glucose (5), TES (100). The $\mathrm{pH}$ was 7.7 at $25^{\circ} \mathrm{C}$ and the osmolality $301 \mathrm{mosmol} / \mathrm{kg}$. Corneas that were to be frozen in air were then transferred to an empty vial but no attempt was made to remove the last traces of solution. The vials were placed in an alcohol bath thermostatically controlled at $-10^{\circ} \mathrm{C}$ for 10 minutes, and freezing was initiated by touching the scleral rim or the immersion solution with a small ice crystal (seeding). Five minutes later the vials were transferred to a programme-controlled cooling apparatus set to cool at $1^{\circ} \mathrm{C}$ per minute to $-70^{\circ} \mathrm{C} .{ }^{16} \mathrm{At}$ this temperature the specimens were transferred to liquid nitrogen $\left(-196^{\circ} \mathrm{C}\right)$ for storage. Thawing was carried out by immersing each vial in a $37^{\circ} \mathrm{C}$ water bath for 3-4 minutes, and removing it just before the last ice had melted. Corneas that had been frozen in air were immersed in $5 \mathrm{ml}$ of 2 molar $\mathrm{Me}_{2} \mathrm{SO}$ in CPTES at $0^{\circ} \mathrm{C}$. All corneas were then transferred into $5 \mathrm{ml}$ of 1 molar $\mathrm{Me}_{2} \mathrm{SO}$ in CPTES, and, at intervals of 5 minutes, first $5 \mathrm{ml}$ of CPTES and then $10 \mathrm{ml}$ was added, producing a final $\mathrm{Me}_{2} \mathrm{SO}$ concentration of 0.25 molar. After 5 minutes in this solution the corneas were transferred to $5 \mathrm{ml}$ of rabbit serum at $0^{\circ} \mathrm{C}$ and allowed to warm to room temperature.

Capella and colleagues' method. The method used in this study was that described by Capella et al. ${ }^{2}$ and is typical of the several related techniques described by these authors. According to this method the corneas were exposed to a series of solutions containing progressively increasing concentrations of $\mathrm{Me}_{2} \mathrm{SO}$ and sucrose. The final solution contained $7 \cdot 5 \% \mathrm{v} / \mathrm{v}$
$\mathrm{Me}_{2} \mathrm{SO}(1 \mathrm{~mol} / \mathrm{l})$. The vials were transferred to an alcohol bath at $-12^{\circ} \mathrm{C}$, seeded, and cooled at $3^{\circ} \mathrm{C}$ per minute to $-70^{\circ} \mathrm{C}$. The vials were then transferred to liquid nitrogen for storage. The corneas were thawed by transferring the vials to a $37^{\circ} \mathrm{C}$ water bath, removing them before the last trace of ice had melted, and placing the corneas in $5 \mathrm{ml}$ of rabbit serum at $0^{\circ} \mathrm{C}$ for 10 minutes. Each cornea was then transferred to a second $5 \mathrm{ml}$ aliquot of rabbit serum at $0^{\circ} \mathrm{C}$ and allowed to warm to room temperature.

\section{TRANSPLANTATION}

Adult Dutch rabbits $(2-3 \mathrm{~kg})$ were anaesthetised by the intramuscular injection of fluanisone and fentanyl citrate (Hypnorm, Jansen $0.5 \mathrm{ml} \mathrm{per} \mathrm{kg}$ ) and intravenous pentobarbitone as required to achieve abolition of the foot withdrawal reflex. Two drops of $1 \%$ amethocaine were applied to the eye and 1000 units of heparin given intravenously. The pupil was widely dilated with $1 \%$ atropine, $1 \%$ cyclopentolate, and $10 \%$ phenylephrine drops. Periorbital hair was trimmed, and the globe was exposed and immobilised with two 4/0 sutures through the extraocular muscles. A $6 \mathrm{~mm}$ corneal button was trephined from the donor cornea on its plastic support ring, and transferred by means of two peripheral $10 / 0$ nylon sutures to a recipient bed of the same diameter. One drop of $2 \%$ methylcellulose was placed on the lens surface to prevent the protuberant lens touching the endothelium. Four temporary interrupted $10 / 0$ nylon sutures secured the graft in position while a continuous $10 / 0$ nylon suture was placed. The anterior chamber was allowed to reform spontaneously, and chloramphenicol and atropine ointments were applied at the end of the procedure. Grafts were performed with corneas from the three experimental groups in random order. The animals were examined by slit-lamp biomicroscopy daily. The only postoperative care required was occasional atropine drops when the pupil was miotic.

\section{METHODS OF ASSESSMENT}

Electron microscopy. Freshly thawed corneas, still mounted on their support rings, were fixed in $3 \%$ glutaraldehyde in 0.15 molar cacodylate buffer $(\mathrm{pH}$ $7 \cdot 2$, osmolality 305 mosmolal before addition of glutaraldehyde). After 24 hours of fixation at room temperature the corneas were removed from the rings, diced, and postfixed in $1 \%$ osmium tetroxide in cacodylate buffer for 1 hour followed by $1 \%$ aqueous uranyl acetate. The specimens were dehydrated in an alcohol series and embedded in Araldite. The sections were cut on an LKB Ultratome 1, stained sequentially with uranyl acetate and lead citrate, and viewed in a Zeiss EM9S2B electron microscope.

Light microscopy. Corneas were fixed in $10 \%$ 

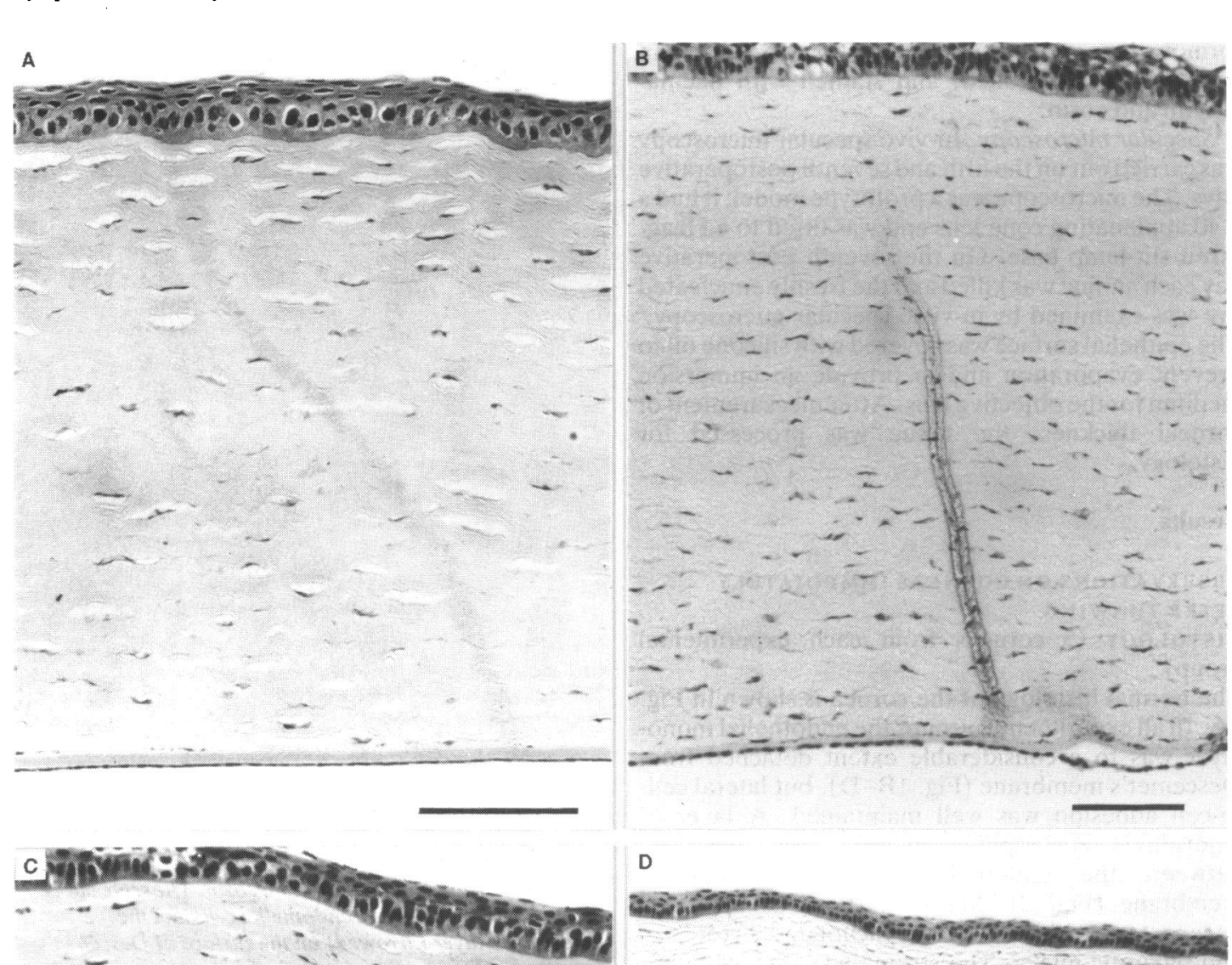

D
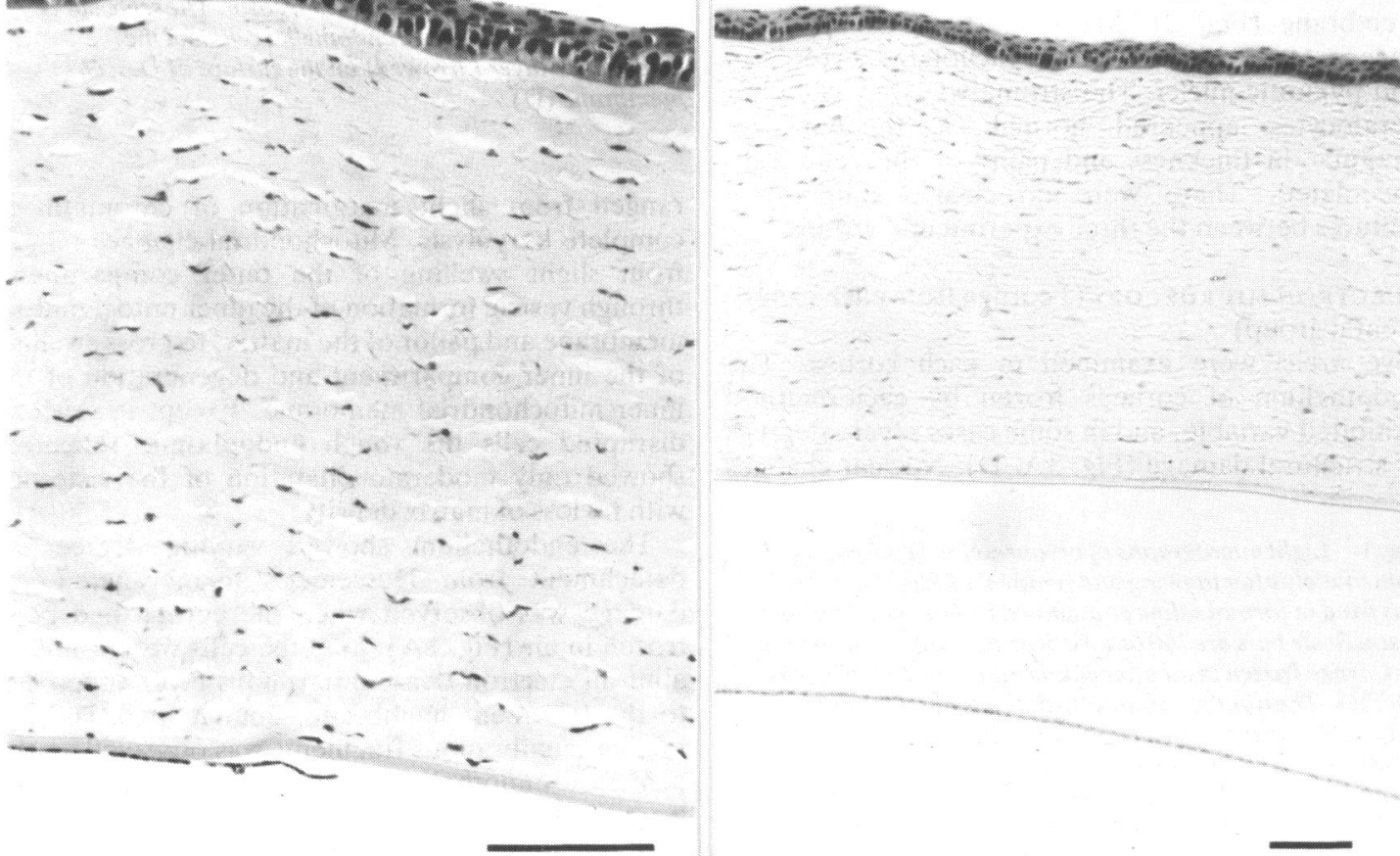

Fig. 1 
formol saline, dehydrated in alcohol, embedded in paraffin wax, sectioned, and stained with haematoxylin and eosin.

Specular microscopy. In-vivo specular microscopy was carried out on the fifth and seventh postoperative days. The microscope was a prototype model; it had a $\times 40$ applanating cone lens and was fitted to a HaagStreit slit-lamp base. On the seventh postoperative day each animal was killed and the freshly enucleated eye was examined by in-vitro specular microscopy. ${ }^{*}$ The epithelial surface was covered with silicone oil to prevent evaporation and to provide an immersion medium for the objective lens. After measurement of corneal thickness the tissue was processed for histology.

\section{Results}

\section{OBSERVATIONS ON CORNEAS IMMEDIATELY}

AFTER THAWING

HISTOLOGY (5 corneas from each experimental group)

The normal histology of the cornea is shown in Fig. 1A. In all experimental groups the endothelial monolayer was to a considerable extent detached from Descemet's membrane (Fig. 1B-D), but lateral cellto-cell adhesion was well maintained. A layer of amorphous eosinophilic material was observed between the endothelium and its basement membrane (Fig. 2). Many of the cells appeared degenerate, with disrupted, vacuolated cytoplasm and pyknotic nuclei. The stroma was thickened but keratocytes appeared normal. Epithelium was irregular in thickness and many of the cells were vacuolated. There were no clear distinguishing features between the three experimental groups.

ELECTRON MICROSCOPY (1 cornea from each experimental group)

Five areas were examined in each cornea. The endothelium of corneas frozen by each method exhibited variable, and in some cases severe degrees of structural damage (Fig. 3A-D). Nuclear changes

Fig. 1 Light micrographs of cryopreserved corneas fixed immediately after thawing and removal of $\mathrm{Me}_{2} \mathrm{SO}$. Tissue was fixed in formol saline and stained by haematoxylin and eosin. Scale bars are $100 \mu \mathrm{m}$. A: Normal, unfrozen cornea. B: Cornea frozen in air after equilibration in $2 \mathrm{M} . \mathrm{Me}_{2} \mathrm{SO}$ CPTES. The number of endothelial cells has not been reduced but there is partial detachment from Descemet's membrane. The stroma is swollen, and the epithelium is variable in thickness and vacuolated. C: Cornea frozen in $5 \mathrm{ml}$ of $2 \mathrm{M} . \mathrm{Me}_{2} \mathrm{SO}-\mathrm{CPTES}$. Some of the endothelium has been lost. D: Cornea frozen by Capella and colleagues' method. The endothelium is completely detached, though cell-to-cell adhesion is maintained.

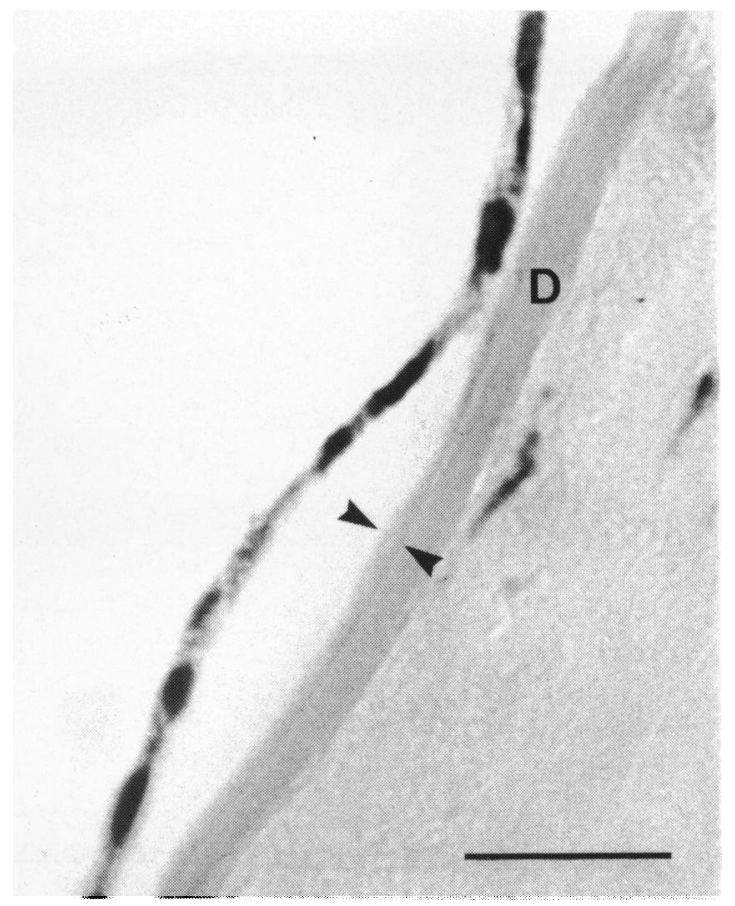

Fig. 2 Light micrograph demonstrating an amorphous layer attached to Descemet's membrane. The cornea had been preserved by the Capella and colleagues' method, and was stained with haematoxylin and eosin. The scale bar is $20 \mu \mathrm{m}$. Note the detached endothelial cells and the amorphous layer (arrowed) on the surface of Descemet's membrane (D).

ranged from slight margination of chromatin to complete karyolysis. Mitochondrial changes ranged from slight swelling of the outer compartment, through vesicle formation of the inner mitochondrial membrane and pallor of the matrix, to gross swelling of the inner compartment and degeneration of the inner mitochondrial membrane. Except in severely disrupted cells the rough endoplasmic reticulum showed only moderate dilatation of the cisternae with no loss of matrix density.

The endothelium showed varying degrees of detachment from Descemet's membrane. Least damage was observed when the cornea had been frozen in air (Fig. 3A): here the cells were found to abut an electron-dense amorphous layer superficial to the basement membrane. Similar material containing membranous fragments was observed on the posterior endothelial surface. Intercellular spaces were of normal width with only slight widening of the tight junctions. Lateral cell-to-cell contact was maintained even in the most severely damaged cells. On the other hand corneas frozen in medium, whether 2 

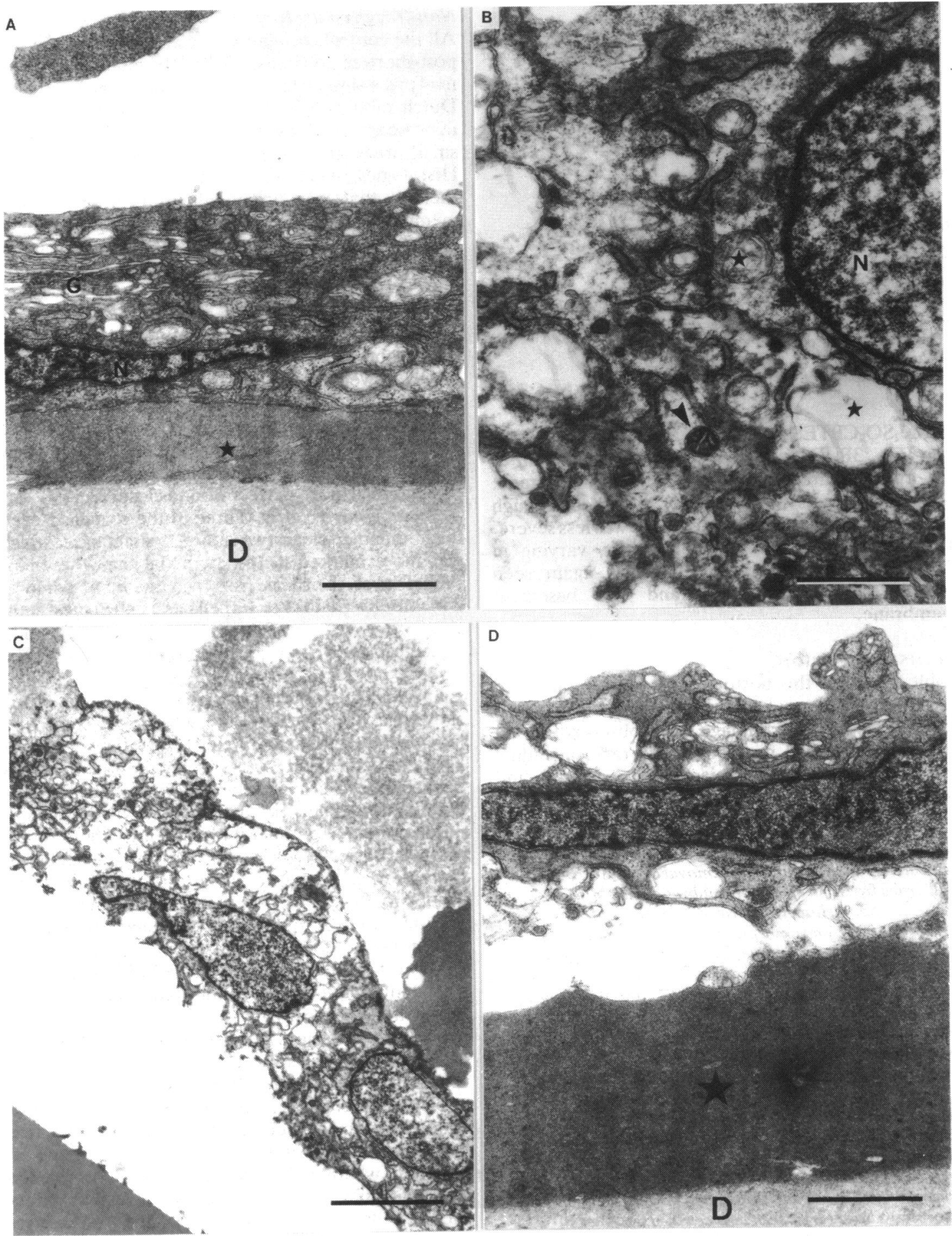

Fig. 3 
Table 1 Results of cornea grafts

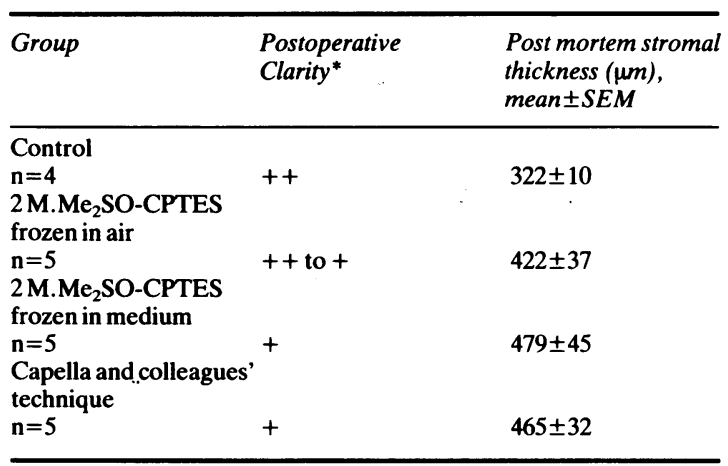

* Graft clarity assessed by slit-lamp biomicroscopy.

$++=$ Clear.

$+=$ Slight opacification, iris details visible.

M.Me ${ }_{2}$ SO-CPTES or Capella and colleagues' solution (Fig. 3B-D), showed extensive detachment of the endothelium from the basement membrane. Most of the cells were severely disrupted, though there were some areas where damage was less severe. The electron dense amorphous layer, varying in thickness from 0.1 to $2.5 \mu \mathrm{m}$, was again seen between the endothelium and the basement membrane.

\section{TRANSPLANTATION}

Table 1 shows the postoperative appearance and post-mortem stromal thickness of the transplanted corneas. Epithelial damage was observed in all grafts, but surgical problems were rare, including only localised iris synechiae to the wound and peripheral vascularisation in two cases.

Fig. 3 Electron micrographs of cryopreserved corneas fixed immediately after thawing and removal of $\mathrm{Me}_{2} \mathrm{SO}$.

A: Cornea frozen in air after equilibration in $2 \mathrm{M} . \mathrm{Me}_{2} \mathrm{SO}$ CPTES. Endothelium is separated from Descemet's membrane (D) by an amorphous layer ( $\star$ ). Some mitochondria appear normal, whereas most show some disorganisation of the cristae, but there is no gross swelling. $\mathrm{N}=$ nucleus. $\mathrm{G}=$ Golgi apparatus. Bar $=1 \mu \mathrm{m}$. B: Cornea frozen in $5 \mathrm{ml} \mathrm{of} 2 \mathrm{M}$.Me 2 SO-CPTES. Some mitochondria are condensed (arrow) but most are swollen ( $\star$ ). The nucleus (N) shows slight margination of heterochromatin, and the rough endoplasmic reticulum is vesiculated. Bar $=1 \mu \mathrm{m}$. C: Lower power view of cornea frozen in $5 \mathrm{ml}$ of $2 \mathrm{M} . \mathrm{Me}_{2} \mathrm{SO}-\mathrm{CPTES}$. The endothelial cells are severely disrupted, but the intercellular junctions remain intact. The endothelium is detached from Descemet's membrane and is overlaid by amorphous debris. Bar $=5 \mu \mathrm{m}$. D: Cornea frozen by the Capella and colleagues' method. A thick amorphous layer ( $\star$ ) is seen between the Descemet's membrane (D) and the disrupted endothelium. Mitochondria are swollen. Bar $=1 \mu \mathrm{m}$.

\section{Non-frozen controls}

All the control corneas were clear, and the range of post-mortem thickness $(322 \pm 10 \mu \mathrm{m}$, mean \pm SEM, $\mathrm{n}=4$ ) was similar to that of normal corneas in adult Dutch rabbits $(321 \pm 8 \mu \mathrm{m}, \mathrm{n}=14)$. In-vivo specular microscopy revealed normal endothelium with only small areas of damage estimated at less than $5 \%$. Histological examination showed an intact endothelium that was firmly adherent to Descemet's membrane (Fig. 4A) and discontinuous from the host endothelium. There was minimal inflammation in the stroma. The epithelium was thin and ulcerated.

\section{Cryopreserved corneas}

General appearance. Immediately after being thawed the cryopreserved corneas appeared thin and clear, but they swelled rapidly. More pressure than normal was required to trephine the disc, and desquamation of both epithelial and endothelial surfaces occurred despite careful surgical technique. The discrepancy between host and graft corneal thicknéss made it difficult to achieve perfect wound closure.

Postoperative clarity. Three of the corneas frozen in air remained clear; two showed a slight haze, which was more marked in the epithelial than the endothelial layer. Corneas frozen in medium, whether $2 \mathrm{M} . \mathrm{Me}_{2} \mathrm{SO}-\mathrm{CPTES}$ or Capella and colleagues' solution, were clear initially but all developed a mild opacification of both epithelial and endothelial layers.

Specular microscopy. In-vivo specular microscopy showed a dark background with bright spots and indistinct lines, but endothelial cell outlines could not be identified. There were no apparent differences between the three experimental groups. The brighter illumination available with the in-vitro specular microscope made it possible to identify the outlines of enlarged endothelial cells, with bright nuclei, in those corneas frozen in air but not in either of the other two groups. Measurement of corneal thickness on the in-vitro microscope revealed swelling to approximately $150 \%$ of control values in all groups: the lowest mean value was obtained with the corneas frozen in air, but there were no statistical differences between the groups.

Histology. Corneas frozen in air had an intact layer of endothelial cells over Descemet's membrane, though the cells were decreased in number and poorly adherent (Fig. 4B). The stroma was thickened, keratocytes were scanty, and the epithelium was thin and ulcerated. The corneas frozen in medium, whether $2 \mathrm{M} . \mathrm{Me}_{2} \mathrm{SO}-\mathrm{CPTES}$ or Capella and colleagues' solution, had very few residual endothelial cells (Fig. 4C and 4D), and those were vacuolated. In all groups the host and graft endothelium was discontinuous (Fig. 4E). Fibroblasts 

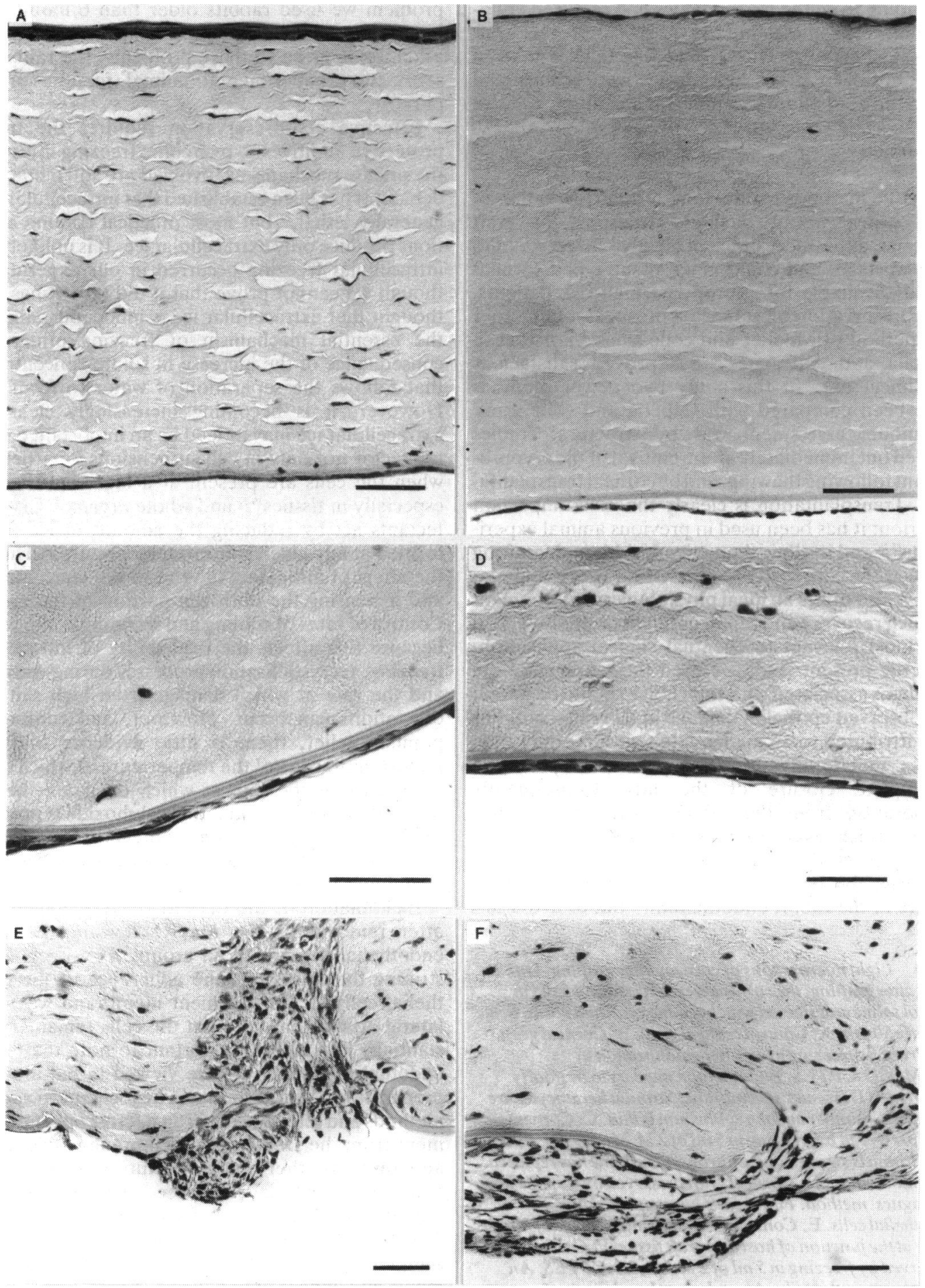

Fig. 4 
extending from the wound edges had replaced endothelium over an estimated $20-60 \%$ of the graft surface (Fig. 4F). The stroma was thicker than in corneas frozen in air, keratocytes were scanty, and again the epithelium was thin and ulcerated.

\section{Discussion}

Effective methods for the long-term preservation of the cornea would facilitate transport of graft material, allow more efficient elective surgery, eliminate wastage, and could make tissue-typed corneas readily available for appropriate high-risk patients. Cryopreservation offers such a prospect, but neither the method of Mueller and colleagues ${ }^{13}$ nor that of Capella and colleagues ${ }^{24}$ has proved satisfactory in clinical use. In this study two newer methods have been compared with Capella and colleagues' technique: assessment was by structural studies carried out immediately after removal of the cryoprotectant following thawing, and by corneal transplantation. Transplantation is clearly the most important criterion: it has been used in previous animal experiments ${ }^{17}{ }^{18}$ and in clinical practice. ${ }^{34}$ Although grafting subjects the cornea to the stress of surgical manipulation, it also offers an ideal physiological environment for such recovery and repair as might be possible, and it is most relevant to eventual clinical application.

In the present study we used the rabbit, and the problems associated with this choice should be noted. We observed epithelial damage in all grafts, and this was attributed to an inadequate tear film: the rabbit blinks unilaterally and slowly, and is prone to incomplete closure of the lids. Consequently evaporation from the rabbit cornea can control corneal thickness even in the absence of endothelial activity, and this must be taken into account in assessing the results. ${ }^{19}$ In addition, mitotic activity occurs in the rabbit endothelium, ${ }^{20}$ but to avoid this

Fig. 4 Light micrographs of corneas after grafting. One week after grafting, the corneas were excised and fixed in formol saline and stained with haematoxylin and eosin. Scale bars are 50 um. A: Control corneal graft. B: Corneal graft, preserved by freezing in air after equilibration in

$2 \mathrm{M} . \mathrm{Me}_{2} \mathrm{SO}-\mathrm{CPTES}$. Endothelium appears to be poorly adherent to Descemet's membrane. Stromal keratocytes are reduced in number and the epithelium is thin. C: Corneal graft preserved by freezing in $5 \mathrm{ml}$ of $2 \mathrm{M}$. Me $\mathrm{e}_{2} \mathrm{SO}$-CPTES. The stroma is swollen and a fibrous membrane has replaced the endothelium. D: Corneal graft preserved by Capella and colleagues' method. Fibroblasts have replaced the

endothelial cells. E: Control graft showing a wedge of fibrous tissue at the junction of host and graft tissue. F: Corneal graft preserved by freezing in $5 \mathrm{ml}$ of $2 \mathrm{M}$.Me $\mathrm{e}_{2} \mathrm{SO}$-CPTES. An extensive growth of fibroblasts has replaced the graft endothelium. problem we used rabbits older than 6 months and killed the animals after one week. Provided proper attention is given to these problems, the rabbit is a satisfactory experimental animal for the present purpose. ${ }^{21}$

Effective cryopreservation requires the use of protective additives to overcome freezing injury, yet the precise mechanisms involved are still a matter of debate. It has been established that intracellular ice is generally lethal, ${ }^{22}$ but most practical cooling conditions produce only extracellular ice. It is unlikely that intracellular freezing occurred in our experiments, though we cannot prove that it did not. It has been thought that extracellular ice is innocuous, and that the essential mechanism of freezing injury is a consequence of the increase in solute concentration that follows the separation of water to form ice. ${ }^{23}$ However, it is becoming increasingly clear that extracellular ice may indeed be an important damaging factor not only in cell suspensions, ${ }^{24}$ particularly when the cells are present at a high density, ${ }^{25}$ but especially in tissues ${ }^{2627}$ and whole organs. ${ }^{28}$ Cryoprotectants act by reducing the amount of ice that is formed at any given subzero temperature. ${ }^{2 y}$ This has the effect of mitigating the rise in salt concentration and increasing the unfrozen portion of the system. Control of rates of cooling and warming is important, because this affects the probability of intracellular freezing, recrystallisation processes during warming, and the rate at which damage from high salt concentrations can occur. However, and contrary to popular belief, there is little evidence that it is important to control the temperature at which freezing occurs or the rate at which the latent heat of fusion is removed. ${ }^{30}$ Dimethyl sulphoxide is probably the most generally used cryoprotectant at present; in these experiments it was used in each of the three techniques investigated.

Examination of the thawed corneas immediately after removal of the $\mathrm{Me}_{2} \mathrm{SO}$ revealed extensive endothelial damage in all groups. However, it was striking that, although the adherence of the endothelial cells to the basement membrane was poor, lateral attachment between the cells remained substantially intact. It is important to note that, when endothelial monolayers are viewed in flat-mounted preparations-for example in histochemical staining methods and scanning electron microscopy-detachment from the Descemet's membrane would not be apparent. Another notable feature was the layer of amorphous material interposed between the basal endothelial surface and Descement's membrane. This layer was present in varying degrees in all the samples examined. It contained membranous fragments and appeared to have been extruded from the damaged endothelial cells, possibly by an exotropic 
blebbing process. ${ }^{31}$ All the cryopreserved corneas were damaged, and no completely normal endothelial cells were seen in any frozen cornea. However, electron microscopy showed that the endothelium of corneas frozen in air was less severely damaged than in the other two groups.

'Success' of the transplanted cornea may be defined by three criteria: a clear graft, a cornea less than twice its normal thickness, and a complete endothelial cell layer. On this basis only those corneas frozen in air after equilibration with 2 $\mathrm{M} . \mathrm{Me}_{2} \mathrm{SO}-\mathrm{CPTES}$ solution can be graded as successful-three complete successes while two, which were slightly cloudy, were regarded as partial successes. None of the corneas that was frozen in medium qualified as successful. In those experiments partial survival of the endothelial cells was associated with decreased clarity and increased corneal thickness. It was not possible to differentiate between either of these two groups by any of the methods used.

It is difficult to compare our results with those previously reported by others, since the method of assessment was quite different. Many such grafted corneas required several weeks to become clear, ${ }^{17}$ and when careful cytological analysis was carried out $^{1 \times 32}$ the results were less impressive and probably comparable, had the methods of assessment been similar, to those reported here. Histological examination of the grafted corneas at one week showed that those that had been frozen in $2 \mathrm{M} . \mathrm{Me}_{2} \mathrm{SO}$ CPTES medium or Capella and colleagues' solution were only partially covered by surviving endothelium, and fibroblasts were found to have repopulated the areas where the graft endothelium had failed to survive. In all cases the graft and host endothelium were discontinuous, and there was no duplication of Descemet's membrane such as would be expected had there been regeneration of endothelial cells, ${ }^{21}$ though one week would be early for such duplication. The surviving cells were reduced in number, enlarged, vacuolated, and poorly adherent to the basement membrane. Mueller' had previously observed such giant cells, and it has been proposed by Neubauer $e t$ al ${ }^{33}$ that their formation may be due to the coalescence of several damaged cells. These pathological giant cells were clearly distinguishable from the giant cells that are quite commonly seen in healthy rabbit corneas. ${ }^{34}$ The reduced number of cells per unit area of cornea in the present experiments is in agreement with the quantitative results of Clifton and Hanna, ${ }^{32}$ Ruusuvaara, ${ }^{35.36}$ and Ehlers et al. ${ }^{37}$ Corneas transplanted after freezing in air had much more complete endothelial layers one week after grafting.

The superiority of corneas frozen in air over those frozen in medium does seem to be clearly estab- lished. This observation was first made by Mueller' on corneas transplanted in dogs and was later confirmed by Taylor et al. ${ }^{8}$ who repeated Mueller's cryopreservation method in the rabbit but assessed function by in-vitro specular microscopy. Sperling ${ }^{38}$ found that the proportion of cryopreserved bovine corneal endothelial cells that excluded trypan blue depended on the volume of solution in which they were frozen; the optimum volume was about $1.5 \mathrm{ml}$ for an $11 \mathrm{~mm}$ button in vials similar to ours. More recently Madden and Easty ${ }^{39}$ have confirmed the value of freezing pig and rabbit corneas in air. The present experiments do not indicate why this technique should be better than the others. It has been established that the distribution of ice within smooth muscle tissue is altered by freezing in air rather than medium, ${ }^{26}$ and it is known that the pattern of ice formation affects functional recovery in this and other tissues. ${ }^{2728}$ Therefore it seems reasonable to propose that changes in the distribution of ice are responsible for the beneficial effect of freezing in air. It is also possible that ice forming between the endothelial cells and Descemet's membrane is responsible for the separation of these two layers.

Clearly these experiments do not provide convincing support for the clinical transplantation of cryopreserved corneas. They do, however, suggest that corneas are better preserved by freezing in air than while immersed in the preservation solution. Further studies, by more precise techniques to quantify the physiological and cytopathological changes that result from freezing, are now needed to elucidate the mechanisms proposed above and to improve the functional quality of cryopreserved corneas.

We acknowledge the technical assistance of B Smith, R Grant, $S$ Gould, and P Davisson. Dr E Sherrard, of the Institute of Ophthalmology, University of London, provided the specular microscopes and much useful advice. A R Hayes gave skilled assistance with temperature measurement.

\section{References}

1 Mueller FO. Short-term experiments on grafting fresh and frozen corneal tissue in dogs. Br J Ophthalmol 1968; 52: 752-62.

2 Capella JA, Kaufman HE, Robbins JE. Preservation of viable corneal tissue. Cryobiology 1965; 2: 116-21.

3 Mueller FO, O'Neill P, Trevor-Roper PD. Full thickness corneal grafts in Addis Ababa, Ethiopia. Br J Ophthalmol 1967; 51: $227-45$.

4 Kaufman HE. Corneal cryopreservation and its clinical application. Transplant Proc 1976; 8 (suppl 1): 149-52.

5 Van Horn DL, Edelhauser HF, DeBruin J. Functional and ultrastructural changes in cryopreserved corneas. Arch Ophthalmol 1973; 90: 312-8.

6 Van Horn DL, Schultz RO. Endothelial survival in cryopreserved human corneas: a scanning electron microscope study. Invest Ophthalmol Vis Sci 1974; 13: 7-16.

7 Kuming BS. The assessment of endothelial viability. S Afr Med J 1969; 43: 1083-5. 
8 Taylor MJ, Hunt CJ, Sherrard ES. Assessment of corneal endothelial integrity by specular microscopy after cryopreservation. The cornea in health and disease (VIth Congress of the European Society of Ophthalmology): Royal Society of Medicine International Congress and Symposium Series no. 40. London: Academic Press and RSM, 1981: 437-44.

9 Madden PW, Easty DL. Assessment and interpretation of corneal endothelial cell morphology and function following cryopreservation. Br J Ophthalmol 1982; 66: 136-40.

10 Edelhauser HF, Van Horn DL, Gallun AB, Schultz RO. Experimental rehydration of cryopreserved corneal tissue. Invest Ophthalmol Vis Sci 1971; 10: 100-7.

11 Elford BC, Walter CA. Effects of electrolyte composition and $\mathrm{pH}$ on the structure and function of smooth muscle cooled to $-79^{\circ} \mathrm{C}$ in unfrozen media. Cryobiology 1972; 9: 82-100.

12 Taylor MJ. The role of $\mathrm{pH}$ and buffer capacity in the recovery of function of smooth muscle cooled to $-13^{\circ} \mathrm{C}$ in unfrozen media. Cryobiology 1982; 19: 585-600.

13 Taylor MJ. Initial studies using a new potassium-rich solution for the cryopreservation of isolated corneas. Cryobiology 1980; 17: 619.

14 Taylor MJ, Hunt CJ. A new preservation solution for storage of corneas at low temperatures. Curr Eye Res 1985; 4: 963-73.

15 Dikstein S, Maurice DM. Metabolic bases to the fluid pump in the cornea. J Physiol (Lond) 1972; 221: 29-41.

16 Hayes AR, Pegg DE, Kingston RE. A multirate small-volume cooling machine. Cryobiology 1974; 11: 371-7.

17 Mueller FO. Techniques for full-thickness keratoplasty in rabbits using fresh and frozen corneal tissue. $\mathrm{Br} \mathrm{J}$ Ophthalmol 1964; 48: 377-93.

18 Lee WR, Mueller FO, Trevor-Roper PD. In-vivo survival of the endothelium of freeze-stored cornea homografts in the rabbit. $\mathrm{Br}$ J Ophthalmol 1967; 51: 321-30.

19 Sherrard ES. Full thickness keratoplasty in the rabbit: an unsatisfactory index of donor integrity. Exp Eye Res 1974; 18: 135-42.

20 Van Horn DL, Sendele DD, Seideman S, Buco PJ. Regenerative capacity of the corneal endothelium in rabbit and cat. Invest Ophthalmol Vis Sci 1977; 16: 597-613.

21 Taylor MJ. Clinical cryobiology of tissues: preservation of corneas. Cryobiology in press.

22 Mazur $P$. The role of intracellular freezing in the death of cells cooled at supraoptimal rates. Cryobiology 1977; 14: 251-72.

23 Lovelock JE. The haemolysis of human red blood cells by freezing and thawing. Biochim Biophys Acta 1953; 10: 414-26.

24 Mazur P, Rall WF, Rigopoulos N. The relative contributions of the fraction of unfrozen water and of salt concentration to the survival of slowly frozen human erythrocytes. Biophys $J 1981$; 36: 653-75.
25 Pegg DE, Diaper MP, Skaer H le B, Hunt CJ. The effect of cooling rate and warming rate on the packing effect in human erythrocytes frozen and thawed in the presence of 2 molar glycerol. Cryobiology 1984; 21: 491-502.

26 Hunt CJ, Taylor MJ, Pegg DE. Frecze substitution and isothermal freeze-fixation studies to elucidate the pattern of ice formation in smooth muscle at $252 \mathrm{~K}\left(-21^{\circ} \mathrm{C}\right) \mathrm{J}$ Microsc 1982; 125: $177-86$.

27 Taylor MJ, Pegg DE. The effect of ice formation on the function of smooth muscle stored at -21 or $-60^{\circ} \mathrm{C}$. Cryobiology $1983 ; 20$ : 36-40.

28 Pegg DE, Jacobsen IA. Current status of cryopreservation of whole organs with particular reference to the kidncy. In: Marberger M, Dreikorn K, Eds. International perspectives in urology: Renal preservation. Baltimore: Williams and Wilkins, 1983: 8.

29 Lovelock JE. The mechanism of the protective action of glycerol against haemolysis by freczing and thawing. Biochim Biophys Acta 1953; 11: 28-36.

30 Foreman J, Pegg DE. Cell preservation in a programmed cooling machine: the effect of varations in supercooling. Cryobiology 1979; 16: 315-21.

31 Hunt CJ, Beadle DJ, Harris LW. An ultrastructural study of the recovery of Chinese hamster ovary cells after freezing and thawing. Cryobiology 1977; 14: 135-43.

32 Clifton EC, Hanna C. Corneal cryopreservation and the fate of corneal cells in penetrating keratoplasty. Am J Ophthalmol 1974; 78: $239-50$.

33 Neubauer L, Laing RA, Leibowitz HM, Oak SS. Coalescence of endothelial cells in the traumatised cornea: I. Experimental observations in cryopreserved tissue. Arch Ophthalmol 1983; 101: $1787-90$.

34 Taylor MJ, Hunt CJ. Dual staining of corneal endothelium with trypan blue and alizarin red $\mathrm{S}$ : importance of $\mathrm{pH}$ for the dye-lake reaction. Br J Ophthalmol 1981; 65: 815-9.

35 Ruusuvaara $\mathbf{P}$. Effects of corneal preservation, donor age, cadaver time and postoperative period on the graft endothelium. A specular microscopic study. Acta Ophthalmol (Kbh) 1979; 57: 868-81.

36 Ruusuvaara $P$. The fate of preserved and transplanted human corneal endothelium. Acta Ophthalmol (Kbh) 1980; 58: 440-53.

37 Ehlers N, Sperling S, Olsen T. Post-operative thickness and endothelial cell density in cultivated, cryopreserved human corneal grafts. Acta Ophthalmol (Kbh) 1982; 60: 935-44.

38 Sperling $\mathrm{S}$. Corneal cryopreservation evaluated by trypan blue staining. Ophthalmic Res 1974; 6: 23-35.

39 Madden PW, Easty DL. An improved method of corneal cryopreservation. Cryobiology 1982; 19: 666-7.

Accepted for publication 20 January 1986. 
I found this book an absolutely delightful volume and one that was extremely hard to put down. It is short enough to be read in just a few sittings and unlike most specialist texts this is not one the reader should dip into selectively. It is a model of clarity and to my mind a superb example of what every multiauthor work should strive to be. I thoroughly recommend it to all with an interest in the underlying aetiology of retinal diseases.

JOHN MARSHALL

Manual of Ocular Diagnosis and Therapy. 2nd Edn. Edited by Deborah Pavan-Langston. Pp. 494. US \$17.95. Little, Brown: Boston, Mass. 1985.

The second edition of this book is welcome as an updated version of a ready reference manual. Although the preface claims it is written for a wide readership, it can be used effectively only by established ophthalmologists and residents in ophthalmology, as considerable clinical knowledge in ophthalmology is an essential prerequisite. There are 15 short chapters written by a panel of 11 ophthalmologists and one neurologist mainly from the Boston hospitals and Harvard Medical School, USA.

The standard selection of chapters covers the field of ophthalmology and neuro-ophthalmology. Clear headings and a concise text are an excellent feature of this manual, though there are very few illustrations indeed, and all blackand-white diagrams. Hence previous clinical knowledge in ophthalmology is essential for the readership. The comprehensive lists of causes and differential diagnosis are very helpful, especially to residents taking examinations and thinking widely on a topic. Established ophthalmologists will find these lists valuable also, making sure they have not forgotten any aspect of a patient's investigations. The lists in chapter 14 of ocular manifestations of systemic disease are comprehensive, and the appendixes $\mathrm{A}$ and $\mathrm{B}$ on common dosages of ophthalmic drugs and antibiotic dosages and routes of administration are especially useful.

The manual is published in soft cover with a spiral binding and may be regarded as an excellent and convenient ready reference book for ophthalmologists and particularly those engaged in postgraduate teaching. The editor and the panel of writers have provided a remarkably concise and comprehensive addition to postgraduate ophthalmic literature. JAMES L KENNERLEY BANKES

\section{Notes}

\section{OSUK Annual Congress}

The Annual Congress of the Ophthalmological Society of the United Kingdom will be held on 8-10 April 1987 at St David's Hall, Cardiff. Applications to present free papers are invited. Details from Mr Z J Gregor, FRCS, Honorary Secretary, Ophthalmological Society of the United Kingdom, 35-43 Lincoln's Inn Fields, London WC2A 3PN.

\section{Multiple sclerosis}

A conference will be held on 3-5 September 1987, at Lyon, France, on 'Trends in European multiple sclerosis research' by the Congress of the European Committee for Therapeutic Research in Multiple Sclerosis (ECTRIMS). Further information from Dr C Confavreux, Hôpital Neurologique, 59 Boulevard Pinel, 69003, Lyon, France.

\section{International Course of Ophthalmology}

This will be held at Barcelona on 24-29 May 1987. Details from Instituto Barraquer, Laforja 88, E-08021 Barcelona, Spain.

\section{Epidemiology and biostatistics}

The National Eye Institute of America will hold a Clinical Vision Research course on 'Epidemiologic and Biostatistical Approaches' at Longboat Key, near Sarasota, Florida, on 29 April to 2 May 1987. Details from Catherine M Beinhauer, Conference Management Associates Inc., 127 Brook Hollow, New Hampshire 03755, USA.

\section{British Contact Lens Association}

Applications are invited for the 1987 Dallos Award, whose object is to support contact lens orientated research. Applications will be accepted only from paid up members of the BCLA. Further details from the association's General Secretary, 14 Perceval Avenue, London NW3 4PY.

\section{Talking newspapers}

Tape recordings from daily newspapers and weekly and monthly magazines are available on tapes playable in ordinary tape players. For $£ 5$ the subscriber receives a 90 -minute tape every week for a year. No postage is required if the subscriber is a registered blind person. Details from Talking Newspaper Association of the UK, 90 High Street, Heathfield, East Sussex TN21 8JD.

\section{Correction}

In the article by L P Fong, C J Hunt, M J Taylor, and D E Pegg on 'Cryopreservation of rabbit corneas: assessment by microscopy and transplantation' (Br J Ophthalmol 1986; 70: 751-60) an error occurred in the second paragraph (page 751). The last three sentences of it should read as follows: 'A similar solution has been proposed for cryopreservation of the cornea. ${ }^{1314}$ It contains the buffer N-tris (hydroxymethyl)-methyl-2-aminoethane sulphonic acid (TES) and is designated CPTES. Specular microscopy has been used to demonstrate that rabbit corneas will tolerate the introduction and removal of 1 and 2 molar $\mathrm{Me}_{2} \mathrm{SO}$ in this solution at $0^{\circ} \mathrm{C}$.' We greatly regret this error, which was due to the transposition of two lines of type. 